\title{
Roles of $\beta$-catenin signaling in phenotypic expression and proliferation of articular cartilage superficial zone cells
}

\author{
Rika Yasuhara ${ }^{1, *, \dagger}$, Yoichi Ohta ${ }^{1, \dagger}$, Takahito Yuasa ${ }^{1, \ddagger}$, Naoki Kondo $^{1, \S}$, Tai Hoang ${ }^{1}$, Sankar Addya ${ }^{2}$, Paolo Fortina ${ }^{2}$, \\ Maurizio Pacifici ${ }^{1}$, Masahiro Iwamoto ${ }^{1}$ and Motomi Enomoto-Iwamoto ${ }^{1}$
}

The superficial zone (SFZ) of articular cartilage has unique structural and biomechanical features, is thought to promote self-renewal of articular cartilage, and is thus important for joint long-term function, but the mechanisms regulating its properties remain unclear. Previous studies revealed that $\mathrm{Wnt} / \beta$-catenin signaling is continuously active in SFZ, indicating that it may be essential for SFZ function. Thus, we examined whether Wnt/ $\beta$-catenin signaling regulates proliferation and phenotypic expression in SFZ cells. Using transgenic mice, we found that acute activation of Wnt/ $\beta$-catenin signaling increases SFZ thickness, Proteoglycan 4 (Prg4, also called lubricin) expression and the number of slow-cell cycle cells, whereas conditional ablation of $\beta$-catenin causes the opposite. We developed a novel method to isolate SFZ cell-rich populations from the epiphyseal articular cartilage of neonatal mice, and found that the SFZ cells in culture exhibit a fibroblastic cytoarchitecture and higher Prg4 and Ets-related gene (Erg) expression and lower aggrecan expression compared with chondrocyte cultures. Gene array analyses indicated that SFZ cells have distinct gene expression profiles compared with underlying articular chondrocytes. Treatment of Wnt3a strongly stimulated SFZ cell proliferation and maintained strong expression of Prg4 and Erg, whereas ablation of $\beta$-catenin strongly impaired proliferation and phenotypic expression. When the cells were transplanted into athymic mice, they formed Prg4- and aggrecan-expressing cartilaginous masses attesting to their autonomous phenotypic capacity. Ablation of $\beta$-catenin caused a rapid loss of Prg 4 gene expression and strong increases in expression of aggrecan and collagen 10, the latter being a trait of hypertrophic chondrocytes. Together, the data reveal that $\mathrm{Wnt} / \beta$-catenin signaling is a key regulator of SFZ cell phenotype and proliferation, and may be as important for articular cartilage long-term function.

Laboratory Investigation (2011) 91, 1739-1752; doi:10.1038/labinvest.2011.144; published online 3 October 2011

KEYWORDS: articular cartilage; $\beta$-catenin; chondrocytes; superficial zone; Wnt signaling

Articular cartilage is an essential component of limb diarthrodial joints and sustains unhindered movement of long bones. When articular cartilage is damaged structurally and/ or functionally by trauma, overuse or inflammation, it is usually unable to fully recover and heal. The tissue is also prone to progressive degeneration during natural aging and other congenital or acquired conditions. Such insufficient recovery abilities and progressive deterioration can lead to severe cartilage damage in joint diseases such as osteoarthritis and rheumatoid arthritis. ${ }^{1-3}$ Thus, it remains very important to understand why articular cartilage has poor repair capacity, and whether it possesses mechanisms and cells potentially able to support repair and self-renewal that could be targeted therapeutically. It is well established that articular cartilage contains several zones characterized by distinct structure, composition and biomechanical properties. ${ }^{4-6}$ The superficial zone (SFZ) is composed of elongated cells that produce high levels of unique molecules including

\footnotetext{
${ }^{1}$ Translational Research Program in Pediatric Orthopaedics, Division of Orthopaedic Surgery, Department of Surgery, Children's Hospital of Philadelphia, Philadelphia, PA, USA and ' ${ }^{2}$ eepartment of Cancer Biology, Kimmel Center, Thomas Jefferson University, Philadelphia, PA, USA

Correspondence: Dr M Enomoto-Iwamoto, PhD, DDS, Translational Research Program in Pediatric Orthopaedics, Division of Orthopaedic Surgery, Department of Surgery, Children's Hospital of Philadelphia 3615 Civic Center Boulevard, ARC 902, Philadelphia PA 19104, USA.

E-mail: iwamotom1@email.chop.edu

${ }^{*}$ Current address: Department of Oral Pathology and Diagnosis, School of Dentistry, Showa University, Tokyo, Japan.

†These authors contributed equally to this study.

${ }^{\ddagger}$ Current address: Department of Orthopaedic Surgery, Juntendo University, School of Medicine, Tokyo, Japan.

${ }^{\S}$ Current address: Department of Orthopaedic Surgery, School of Medicine, University of Niigata, Niigata, Japan.
}

Received 15 February 2011; revised 28 July 2011; accepted 17 August 2011 
tenascin-C, the Ets-related gene transcription factor (Erg) and Proteoglycan 4 (Prg4), but relatively low levels of aggrecan. ${ }^{6-10}$ This combination of phenotypic traits is thought to be important for SFZ function and overall joint mechanics and lubrication. ${ }^{11-14}$ Interest in SFZ biology has been re-invigorated by recent studies, suggesting that it may contain cells with stem or progenitor capacity. ${ }^{15,16}$ Dowthwaite et $a l^{15}$ isolated SFZ cells from postnatal bovine articular cartilage using differential adhesion to fibronectin-coated substrates. They found that the cells have progenitor characteristics based on the high colony formation capacity and Notch 1 expression, and can acquire and express a chondrogenic phenotype over passage number. Thus, SFZ cells may normally act in self-renewal and maintenance of articular cartilage.

In addition to the above gene products, SFZ cells express specific signaling molecules that include members of the Wnts, bone morphogenetic proteins, and transforming growth factor families and their receptors and modulators. ${ }^{6,17}$ However, it remains unclear whether and how these and/or other signaling factors regulate the nature and phenotype of SFZ. Elucidation of the roles of these pathways would be important, as it could lead to therapeutic strategies to promote articular cartilage repair and restore structural and functional homeostasis. We reported recently that $\mathrm{Wnt} / \beta$-catenin signaling is particularly high in SFZ cells, and that ablation of $\beta$-catenin leads to loss of SFZ cells, whereas transient signaling stimulation induces SFZ thickening. ${ }^{18}$ These findings indicate that $\mathrm{Wnt} / \beta$-catenin signaling may be a critical regulator of behavior and function of SFZ cells in addition to its important roles in cartilage development and function. ${ }^{6,19-22}$ To gain a better understanding of the roles of $\mathrm{Wnt} / \beta$-catenin signaling in SFZ function, we determined the cellular and molecular changes induced by activation and inactivation of Wnt/ $\beta$-catenin signaling in transgenic mice and SFZ mouse cell cultures. Our data do indicate that $\mathrm{Wnt} / \beta$-catenin signaling is required for proliferation and phenotypic expression of SFZ cells.

\section{MATERIALS AND METHODS Transgenic Mice}

All studies were conducted with approval by the IACUC. We recently described the creation of Col11-CA- $\beta$ catER mice that harbor an $\mathrm{N}$-terminally-truncated $\beta$-catenin linked to a modified estrogen receptor (ER) ligand-binding domain under the control of collagen 11 promoter/enhancer. ${ }^{23}$ To activate $\mathrm{Wnt} / \beta$-catenin signaling, 2-week-old Col11-CA$\beta$ catER transgenic mice were injected with tamoxifen for 7 days, with doses up to $200 \mu \mathrm{g} / 20 \mu \mathrm{l}$ per mouse as described previously. ${ }^{23}$ Control mice received the same volume of vehicle cocktail (10\% ethanol and $90 \%$ corn oil). Three wild type and three transgenic mice were killed 2 weeks after the last tamoxifen or vehicle administration. Hind limbs were dissected and subjected to histopathological analyses.
Col2CreER; $\beta$-catenin ${ }^{f l f l}$ mice: mice conditionally deficient in $\beta$-catenin were created by mating $\beta$-catenin-floxed mice $\left(\beta\right.$-catenin $\left.{ }^{f l / f 1}\right)$ possessing loxP sites in introns 1 and 6 in the $\beta$-catenin gene (6.129-Ctnnb1tmKem/KnwJ line purchased from the Jackson Laboratory, Bar Habor, ME, USA) with Col2a1-CreER mice (kindly provided by Dr S Mackem, NIDCR). ${ }^{24}$ To ablate the $\beta$-catenin gene, we injected tamoxifen at a dose of $100 \mu \mathrm{g} / 10 \mu \mathrm{l}$ volume per mouse per day on postnatal day 5, 6 and 7 (P5 to P7). Mice (three $\beta$ - catenin $^{f l / f l} ;$ Col2a1-CreER mice and three $\beta$-catenin ${ }^{f l / f l}$ mice) were then killed at 7 weeks of age. Efficiency of Cre recombinase activity was confirmed by analysis of compound Col2a1-CreER/Rosa R26R transgenic-reporter mice following a similar regimen of tamoxifen injections. CagCreE; $\beta$-catenin $^{f l / f l}$ mice were mated with $\beta$-catenin ${ }^{f l / f l}$ mice, which have a tamoxifen-inducible Cre-mediated recombinase system driven by the chick $\beta$-actin promoter/enhancer coupled to the cytomegarovirus immediate-early enhancer (CagCreER; B6.Cg- $\mathrm{Tg}\left(\mathrm{CAG}-\mathrm{cre} / \mathrm{Esr}^{*}\right)$ 5Amc/J purchased from the Jackson Laboratory). Ablation of $\beta$-catenin was induced by treatment with $1 \mu \mathrm{M}$ 4-hydroxytamoxifen (4OTH; SigmaAldrich, St Louis, MO, USA) in culture. Gdf5Cre;Rosa26R mice: Gdf-5-Cre transgenic mice were described previously, ${ }^{25}$ and line $\mathrm{B}$ was used in the present study. Mice were mated with Rosa R26R Cre-inducible LacZ ( $\beta$-galactosidase) mice in which the reporter $\beta$-galactosidase gene is silent and becomes irreversibly expressed after Cre recombinase removal of a floxed silencer within its constitutive promoter reporter mice. ${ }^{26}$

\section{Histological Examination and In Situ Hybridization}

Knee joints were dissected after perfusion fixation with $4 \%$ (v/v) paraformaldehyde, decalcified with EDTA for 3-5 days and embedded in paraffin. Sections ( $6 \mu \mathrm{m}$ thick) were subjected to staining with hematoxylin and eosin (H\&E) or bromodeoxyuridine (BrdU) immunostaining. Sections were also used to examine Prg4 expression by in situ hybridization using ${ }^{35}$ S-labeled riboprobes of a 2605-bp mouse Prg4 gene fragment (41-2646; AB034730). Frozen sections of knee joints were prepared from P5 mouse and stained with alpha 5 integrin antibodies (1:200; CD49e, BD Biosciences, San Jose, CA, USA).

Transplants were fixed with $4 \%$ paraformaldehyde and embedded in paraffin or OTC compound. Sections were subjected to staining with $\mathrm{H} \& \mathrm{E}$ or alcian blue ( $\mathrm{pH}$ 1.0). Detection of $\beta$-galactosidase activity was preformed using X-gal substrate (Millipore, Billerica, MA, USA) and $\beta$-galactosidase stain base solution (Millipore). Immunostaining for collagen 2 was performed by incubation with anti-bovine collagen 2 polyclonal antibodies (1:200, Cosmo Bio USA, Carlsbad, CA, USA) followed by incubation with Alexa fluor 594-labeled anti-rabbit immunoglobulins (IgGs) (1:200, Invitrogen, San Diego, CA, USA). Parallel control sections were incubated with preimmune rabbit IgGs ( $5 \mu \mathrm{g} / \mathrm{ml}$, Vector Laboratories, Burlingame, CA, USA). 


\section{BrdU Labeling and Detection}

Mice received a daily intraperitoneal injection of BrdU $(25 \mathrm{mg} / \mathrm{kg}$, Invitrogen), five times starting at P11. Longitudinal long bone sections were incubated with anti-BrdU antibodies (1:200, Roche Diagnostics, Indianapolis, IN, USA) followed by incubation with Alexofluor 488-anti mouse IgG. In these experiments, we used three mice per group. Three slides per sample were subjected to BrdU staining, and three independent regions per slide were examined. Similar results were obtained in all examined samples.

\section{SFZ Cell and Chondrocyte Cultures}

The proximal end of femur and distal end of tibia were dissected from neonatal mouse (P3-P5) knee joints, and ligaments and tendons were carefully excised from their attachment sites by a surgical knife with the aid of a stereomicroscope. Tissues were incubated with $0.25 \%$ trypsin (Invitrogen; w/v) for $1 \mathrm{~h}$, followed by $1.5 \mathrm{~h}$ digestion with $173 \mathrm{U} / \mathrm{ml}$ type 1 collagenase (Worthington Biochemical, Lakewood, NJ, USA). Dissociated cells (500 000 cells $/ 100 \mathrm{~mm}$ dish) were seeded on culture dishes pre-coated with $0.1 \%$ plasma fibronectin solution (GEMINI Bio-Products, West Sacramento, CA, USA) for $2 \mathrm{~h}$, followed by blocking with $3 \%$ BSA for $30 \mathrm{~min}$. The unattached cells were washed out with Dulbecco's modified Eagle medium (DMEM) twice $20 \mathrm{~min}$ after plating, and the attached cells were maintained in DMEM containing $10 \%(\mathrm{w} / \mathrm{v})$ fetal bovine serum (FBS; GEMINI). SFZ cells were subcultured at a 1:10 ratio into uncoated culture dishes when subconfluent. The SFZ cells were transferred to pellet culture ( 200000 cells per pellet) after six passages. Chondrocytes were isolated by additional overnight collagenase digestion of residual epiphyseal cartilage tissue as previously described. ${ }^{27}$ Cultures were treated with recombinant mouse Wnt3a (rWnt3a) (Chemicon, Temecula, CA, USA), conditioned medium containing Wnt $3 \mathrm{a}^{27} \mathrm{Wnt} / \beta$-catenin signaling inhibitors (recombinant mouse Dkk-1 (R\&D systems), IWR-1-endo (Santa Cruz Biotechnology), KN-93 (an effective inhibitor of $\mathrm{Ca} 2+1$ calmodulin-dependent protein kinase II, Santa Cruz Biotechnology) or SP600125 (a selective inhibitor of c-Jun $\mathrm{N}$-terminal kinases, Santa Cruz Biotechnology).

\section{Transfection and Wnt Reporter Assays}

SFZ cells were plated at an initial density of $2 \times 10^{4}$ per well into 96-well plates that had been pre-coated with a Wnt/ $\beta$-catenin reporter plasmid (Super $8 \times$ TOPFlash, Addgene Cambridge MA, USA) in the presence of Lipofectamine 2000 (Invitrogen). After $24 \mathrm{~h}$, cultures were treated with rWnt3a $(100 \mathrm{ng} / \mathrm{ml})$ and/or recombinant mouse Dkk-1 $(100 \mathrm{ng} / \mathrm{ml}$, IWR-1 $(10 \mu \mathrm{M})$ and $6 \mathrm{BIO}(1 \mu \mathrm{g} / \mathrm{ml}$, Enzo Life Sciences International, Plymouth Meeting, PA, USA), and luciferase activity was measured using Bright-Glo assay kit (Promega, Madison, WI, USA). Super $8 \times$ TOPFlash encodes seven copies of LEF/TCF binding sites linked to firefly luciferase and reflects $\mathrm{Wnt} / \beta$-catenin signaling activity.

\section{RNA Isolation and Gene Expression Assays}

Total RNA was isolated using TRIzol reagent (Invitrogen) following manufacturer's protocol, and reverse-transcribed into cDNA. The resulting cDNA was reverse transcribed and subjected to PCR or quantitative PCR assays. Real-time PCR was performed with an Applied Biosystems 7900HT Sequence Detection Systems running SDS 2.1 software using SYBR green (Applied Biosystems, Foster City, CA, USA). Average threshold cycle value (Ct value) was calculated from triplicate reactions. Standard curves were generated using 10 -fold serial dilutions of cDNA of each gene, with a correlation coefficient of $>0.98$. Relative expression levels were calculated based on a standard curve, and normalized to glyceraldehyde 3-phosphate dehydrogenase (Gapdh). Primers are designed to amplify sequences common among known splice variants of each gene. Primer sequences used for realtime PCR amplification were as follows: $5^{\prime}$-TCT GGA AAT GAC AAC CCC AAG CAC A- $3^{\prime}$ and $5^{\prime}$-TGG CGG TAA CAG TGA CCC TGG AAC T-3' for 5463-5939 of mouse Aggrecan (NM_007424), 5'-CTT GTG GAC AAT CCT CAG GTT TCT GTT C- $3^{\prime}$ and $5^{\prime}$-TCG GTC ACC ATC AAT GCC ATC TAT G-3' for 822-1040 of mouse Collagen 9 (a1) (NM_007740), $5^{\prime}$-TGC TGC TAA TGT TCT TGA CCC TGG TTC- $3^{\prime}$ and $5^{\prime}$-ATG CCT TGT TCT CCT CTT ACT GGA ATC C- $3^{\prime}$ for 717-876 of mouse collagen 10 (a1) (NM_009925), 5'-TGG AGT GCT GTC CTG ATT TCA AGA G-3' and $5^{\prime}$-GGT GAT TTG GGT GAG CGT TTG GTA- $3^{\prime}$ for $201-456$ of mouse Prg4 (NM_021400), 5'-CAC CAT CTC CAC CAC GCA GAA T- $3^{\prime}$ and $5^{\prime}$-TGC TGA ATG TTG CCA CCT CTC TTG- $3^{\prime}$ for 34-310 of mouse Prg4 (NM_021400), 5'-TGG GAT TGG TTC TGC TGT CAA G- $3^{\prime}$ and $5^{\prime}$-CAT TTC TTC CGT GGA TGC CTT CAC- $3^{\prime}$ for mouse tenascin $C$ (NM-011607), 5'-CCA GCG TCC TCA GTT AGA TCC TTA CCA-3' and 5'-TCA TGT TGG GCT TGC TCT TCC TCT C-3' for 1123-1349 of mouse Erg (NM_133659), 5'-CCA GGA GAA CCC CAA GAT GCA CAA- $3^{\prime}$ and $5^{\prime}$-TCA TGC TGT AGC TGC CGT TGC TC-3' for 597-937 of mouse SOX 2 (NM_011443), 5'-GGC GTT CGC TTT GGA AAG GTG TTC- $3^{\prime}$ and $5^{\prime}$-CTC GAA CCA CAT CCT TCT CT- $3^{\prime}$ for 554-866 of mouse Oct4 (NM_013633), $5^{\prime}$-GGT GTT CCT GGT CCT CGT TT- $3^{\prime}$ and 5'-CAA AGG AGG TGA CAA TGC TGG-3' for 648-1306 of mouse CD105 (NM_007932), and 5'-AAG CCC ATC ACC ATC TTC CAG GAG- $3^{\prime}, 5^{\prime}$-ATG AGC CCT TCC ACA ATG CCA AAG-3' for 258-568 of Gapdh (NM_008084), using proper filters to visualize fluorescent markers.

Prg4 gene expression was also determined by the Taqman gene expression assay, using pre-designed Taqman probe and primers (Assay ID: Mm00502413_m1). The primer set amplifies part of exon 10-12 of Prg4 (NM_021400.3), the region which is common among all known Prg4 isoforms.

First-strand cDNA was synthesized from $1 \mu \mathrm{g}$ of total RNA with $1 \mu \mathrm{M}$ of random 6 -mer primer (Perkin Elmer) using SuperScript II TM reverse transcriptase (GIBCO BRL, Gaithersburg, MD, USA) at $42{ }^{\circ} \mathrm{C}$ for $45 \mathrm{~min}$. Subsequent amplification was performed with Go-taq (Sigma) by incubation 
at $95^{\circ} \mathrm{C}$ for $3 \mathrm{~min}, 25-30$ cycles (27 for $\operatorname{Prg} 4 ; 30$ for $\operatorname{Erg}$ and CD105; 25 for Gapdh) of $95^{\circ} \mathrm{C}$ for $30 \mathrm{~s}$ and $60^{\circ} \mathrm{C}$ for $30 \mathrm{~s}$, followed by incubation at $72{ }^{\circ} \mathrm{C}$ for $10 \mathrm{~min}$. Primer sequences for PCR amplification are described above. Primer sequences for Prg4 are 5'-TGG AGT GCT GTC CTG ATT TCA AGA G$3^{\prime}$ and $5^{\prime}$-GGT GAT TTG GGT GAG CGT TTG GTA- $3^{\prime}$ for 201-456 of mouse Prg4 (NM_021400).

To analyze gene expression of Wnts, we carried out PCR analysis using RT2 Profiler PCR array for Wnt signaling pathway (Superarray, Frederick, MD, USA) following the manufacturer's protocol. Average Ct value was calculated from four-fold reactions and normalized to that of housekeeping gene Gapdh. These experiments were repeated twice independently.

\section{Gene Arrays}

SFZ cells and chondrocytes were isolated from compound transgenic mice (five mice per experiment) of Gdf5Cre; Rosa26-EYFP (B6.Cg-Gt(ROSA)26Sortm3.1(CAG-EYFP) Hze/J, The Jackson Laboratories) as described above. Pure populations of SFZ cells and articular chondrocytes were isolated as enhanced-yellow fluorescent protein (EYFP)positive and -negative cells by flow cytometry in our central facility, respectively, and were immediately used for total RNA preparation without expansion. Two independent RNA samples were prepared for SFZ cells and articular chondrocytes.

Total RNAs were isolated from using a RNeasy Mini Kit and a RNeasy MinElute Cleanup kit (Qiagen Valencia, CA). DNase-treated RNA was ethanol precipitated and quantified on a NanoDrop ND-1000 spectrophotometer, followed by RNA quality assessment by analysis on an Agilent 2100 bioanalyzer (Agilent, Palo Alto, CA, USA). RNA amplification and labeling were performed by the WT-Ovation Pico RNA amplification system (NuGen Technologies) as described previously. ${ }^{28}$ Each Affymetrix gene chip mouse exon 1.0 ST array (Affymetrix, Santa Clara, CA, USA) was hybridized with fragmented and biotin-labeled target for $18 \mathrm{~h}$. Arrays were then washed and stained using Genechip Fluidic Station 450, and hybridization signals were amplified using antibody amplification with goat IgG (Sigma-Aldrich) and anti-streptavidin biotinylated antibody (Vector Laboratories). Chips were scanned on an Affymetrix Gene Chip Scanner 3000, using Command Console Software. Background correction and normalization were done using Robust Multichip Average (RMA) with Genespring V 10.0 software (Agilent). Volcano plot was used to identify differentially expressed gene list using the unpaired two-sample Student's $t$-test, as well as $P$-value less than or equal to 0.05 , and fold change more than or equal to 2. The differentially expressed gene list was loaded into Ingenuity Pathway Analysis 5.0 software (http://www. ingenuity.com) to perform biological network and functional analyses. ${ }^{29}$

\section{Transplants}

SFZ cells were harvested and mixed with a collagen solution (3 mg/ml, Cellmatrix, Nitta Gelatin, Osaka, Japan) at a concentration of $6.0-8.0 \times 10^{6} / \mathrm{ml}$ following the manufacturer protocol. The cell mixture $(250 \mu \mathrm{l}$ per mouse) was subcutaneously injected in athymic mice (CD-1 Nude Mouse, Charles River Laboratories International, Wilmington, MA, USA). Transplanted cells were collected 1 week later, and subjected to histological inspection or preparation of total RNA.

\section{Statistical Analysis}

Student's $t$-test was used to determine statistical significance between groups. $P$-values less than 0.01 were considered significant $\left({ }^{\star} P<0.01\right.$ as indicated by bars).

\section{RESULTS \\ Modulation of Articular Cartilage SFZ Organization by $\beta$-Catenin Signaling}

We previously created the transgenic mouse line Col11-CA$\beta c a t E R$ in which $\beta$-catenin signaling can be transiently activated in cartilage by tamoxifen administration, and we showed that signaling activation leads to significant changes in articular cartilage SFZ. ${ }^{23}$ To better understand the nature of these changes and their underlying mechanisms, 2 weekold Col11-CA- $\beta$ catER mice received a daily injection of tamoxifen (or vehicle) for 7 days, and their limb joints were examined 2 weeks after the last injection. We found that their tibial SFZ was considerably thicker and displayed a proportional increase in cell number (Figure 1b), compared with that in companion vehicle-treated transgenic or wild-type mice in which it had its typical thin appearance and organization (Figure 1a). To determine whether such structural change was associated with phenotypic changes, we examined expression of Prg4, a key extracellular protein

Figure 1 Changes in articular cartilage organization, Proteoglycan 4 (Prg4) expression and slow-cell cycle cell number following $\beta$-catenin signaling modulation. (a-I), 2 week-old Col11-CA- $\beta$-catER transgenic mice (b, e, $\mathbf{f}, \mathbf{i}$, j and $\mathbf{I}$ ) and wild-type littermates (a, $\mathbf{c}, \mathbf{d}, \mathbf{g}, \mathbf{h}$ and $\mathbf{k})$ received seven daily peritoneal injections of tamoxifen $\left(200 \mu \mathrm{g} / 20 \mu \mathrm{l} /\right.$ mouse) and were killed at 7 weeks of age. $(\mathbf{m}-\mathbf{x}), \beta$-catenin ${ }^{\text {fl/fl }}$ (m, o, p, s, t and $\left.\mathbf{w}\right)$ or Col2CreER; $\beta$-catenin ${ }^{\text {fl/fl }}$ (n, $\mathbf{q}, \mathbf{r}, \mathbf{u}, \mathbf{v}$ and $\mathbf{x}$ ) mice received three daily peritoneal injections of tamoxifen (100 $\mu \mathrm{g} / 10 \mu \mathrm{l} / \mathrm{mouse})$ starting at P5 and were sacrificed at 7 weeks. Some mice ( $\mathbf{k}, \mathbf{I}, \mathbf{w}$ and $\mathbf{x})$ also received a daily intraperitoneal injection of bromodeoxyuridine (BrdU) $(25 \mathrm{mg} / \mathrm{kg})$ five times starting from P11. Longitudinal sections of proximal tibial articular cartilage were stained with hematoxylin and eosin ( $\mathrm{HE} ; \mathbf{a}, \mathbf{b}, \mathbf{m}$ and $\mathbf{n}$ ) or processed for in situ hybridization analysis of Prg4 (c, e, $\mathbf{g}, \mathbf{i}, \mathbf{0}, \mathbf{q}, \mathbf{s}$ and $\mathbf{u}$ for dark field images and $\mathbf{d}, \mathbf{f}, \mathbf{h}, \mathbf{j}, \mathbf{p}, \mathbf{r}, \mathbf{t}$ and $\mathbf{v}$ for bright field images). White arrows indicate BrdU-labeled cells (k, I and $\mathbf{w})$. Bars represent: $10 \mu \mathrm{m}$ for $\mathbf{a}, \mathbf{b}, \mathbf{m}$ and $\mathbf{n} ; 80 \mu \mathrm{m}$ for $\mathbf{c}-\mathbf{j}$ and $\mathbf{o}-\mathbf{v}$; and $6.7 \mu \mathrm{m}$ for $\mathbf{k}, \mathbf{I}, \mathbf{w}$ and $\mathbf{x}$. 


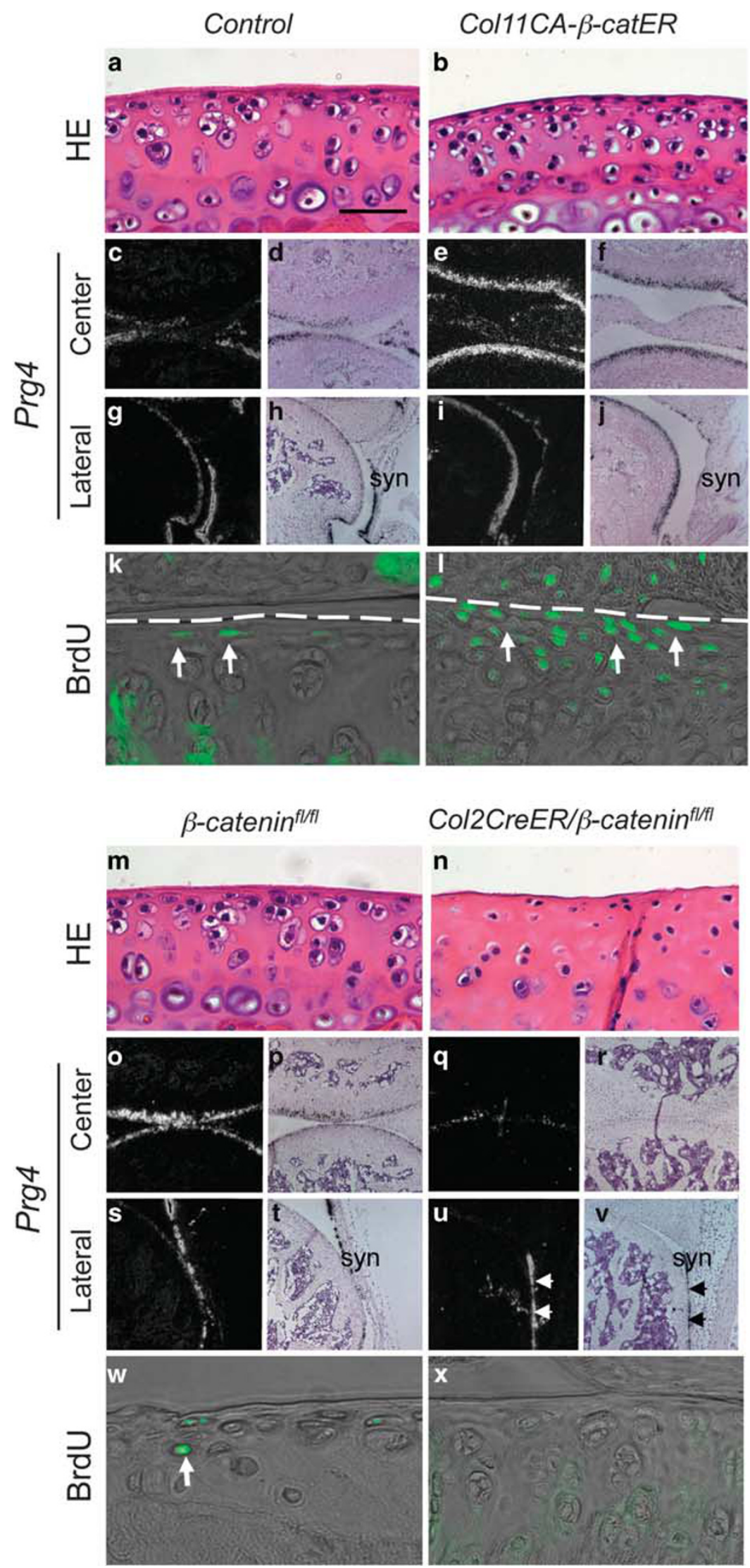


needed for joint lubrication and specifically expressed by SFZ cells. ${ }^{30-33}$ In controls, Prg4 expression was restricted to the thin SFZ layer in both center (Figures $1 \mathrm{c}$ and d) and lateral side (Figures $1 \mathrm{~g}$ and $\mathrm{h}$ ) of articular cartilage and synovium (Figures $1 \mathrm{~g}$ and $\mathrm{h}$, syn). In tamoxifen-treated Col11-CA$\beta$ catER mice, however, Prg4 expression encompassed the entire and thickened SFZ tissue (Figures 1e, f, i and j), whereas it had not increased in synovium (Figures $1 \mathrm{i}$ and $\mathrm{j}$, syn). Tissue architecture and Prg4 expression were not affected in control wild-type mice subjected to the same regiment of tamoxifen injection as previously reported. ${ }^{23}$

In very good agreement, we observed the opposite responses when $\beta$-catenin was conditionally ablated in cartilage after tamoxifen injection of Col2CreER; $\beta$-catenin ${ }^{f l f l}$ mice. Thus, although control mice displayed a typical SFZ with typical Prg4 expression (Figures 1o, p, s and t), the cell number in SFZ was severely reduced, and Prg4 expression was barely detected in companion $\beta$-catenin-deficient mice (Figures $1 \mathrm{q}, \mathrm{r}, \mathrm{u}$ and $\mathrm{v}$ ). Prg4 transcripts were normal in synovium in tamoxifen injected Col2CreER; $\beta$-catenin ${ }^{\text {flfl }}$ mice (Figures $1 \mathrm{u}$ and $\mathrm{v}$, arrows), indicating that the decrease in Prg4 expression in the SFZ was specific and reflected sitespecific $\beta$-catenin deficiency.

The changes in SFZ cellularity following activation or inactivation of $\beta$-catenin signaling indicate that this pathway may be very important in regulating local proliferative activity. In addition, the SFZ is thought to contain slow cellcycle cells that would sustain long-term self-renewal and maintenance of articular cartilage. ${ }^{34,35}$ Thus, we examined whether modulation of $\mathrm{Wnt} / \beta$-catenin signaling affected such slow cell-cycle population. To do so, we injected BrdU in Col11-CA- $\beta$ catER or Col2CreER; $\beta$-catenin ${ }^{f l f l}$ mice at postnatal stages and induced activation or inactivation of Wnt/ $\beta$-catenin signaling by tamoxifen injections, respectively. Mice were then maintained for up to 7 weeks from the last injection, and their knee joints were analyzed for presence and distribution of BrdU-labeled cells. We found that in control mice, the SFZ (but not the deep zones) still contained BrdU-labeled cells after 6-8 weeks (Figures $1 \mathrm{w}$ and $\mathrm{k}$, arrows), indicating that the SFZ contains long-lasting slow-cell cycle cells as previously reported. ${ }^{34}$ Activation of $\mathrm{Wnt} / \beta$-catenin signaling led to a significant increase in labeled cells in SFZ (Figure 1l, arrows), whereas deletion of $\beta$-catenin clearly diminished the size of that cell population (Figure 1x). These findings indicate that $\mathrm{Wnt} / \beta$-catenin signaling strongly influences the organization of articular cartilage and particularly its SFZ structure, and may regulate Prg4 expression and the slow cell-cycle population in the SFZ.

\section{Isolation and Testing of SFZ Cells}

To be able to study more directly how modulations of the Wnt/ $\beta$-catenin signaling affect SFZ cells, we set out to establish a method by which the cells could be effectively isolated from articular cartilage of postnatal mice, and studied in vitro. To this end, we microsurgically isolated the epiphyseal cartilaginous ends of knee long bones of neonatal mice, free of adjacent ligaments and other connective tissues, and subjected them to a 1-h trypsin incubation followed by a 1.5-h collagenase incubation. The trypsin digestion removed residual soft tissues around the epiphysis (Figure 2a), whereas the collagenase digestion rendered the articular cartilage superficial uneven (Figure $2 c$, arrows), indicating that it had removed SFZ cells. To confirm that this short collagenase incubation largely, if not exclusively, removed the SFZ, but not the entire articular cartilage, we used similar epiphyseal ends isolated from Gdf5Cre;RosaR26R mice in which the entire articular layers, but not secondary ossification center and underlying growth plate cartilage, are $\beta$-galactosidase positive. ${ }^{18,25}$ After the trypsin incubation, the epiphyseal pieces still contained $\beta$-galactosidase-positive cells and had a smooth contour (Figure $2 \mathrm{~b}$ ). After the collagenase digestion, the outer perimeter of the articular cartilage had become rough, but still contained numerous $\beta$-galactosidase-positive chondrocytes (Figure 2c), indicating that the collagenase treatment released SFZ cells, but had left the articular chondrocyte population behind and largely intact. To further purify the SFZ cells, we exploited the fact that SFZ cells strongly and selectively express $\alpha 5$ integrin, ${ }^{15}$ which we confirmed by immunostaining (Figure $2 \mathrm{~d})$. Thus, we allowed the collagenase-released cells to adhere to fibronectin-coated substrates for 15-20 min, and removed unattached cells by washing. The attached cells, representing highly enriched SFZ cells, were then maintained in 10\% FBS containing Dulbecco modified Eagle medium. To isolate chondrocytes, the residual cartilaginous tissue following the 1.5-h collagenase digestion was incubated in collagenase overnight, and the released chondrocytes were maintained under similar culture conditions.

Microscopic analysis showed that the SFZ cells displayed an elongated and fibroblastic cytoarchitecture (Figure 2e, SFZ), whereas chondrocytes were polygonal and epithelioid as to be expected (Figure 2f, CC). Total RNAs isolated from SFZ and chondrocyte cultures were processed for reverse transcribed-PCR analysis to assess the phenotypic characteristics of each population. The SFZ cells strongly expressed Prg4, $\operatorname{Erg}$ and tenascin $C$, all of which are abundant gene products in articular cartilage superficial, ${ }^{10,18}$ whereas chondrocytes displayed much lower expression of these genes (Figure 2g). Expression of collagen 9 a1 (Col9a1), aggrecan (Acan) and matrilin-1 (Mat-1) was much lower in SFZ cells than chondrocytes (Figure $2 \mathrm{~h}$ ). Interestingly, SFZ cultures also expressed stem cell markers including Sox2, CD34 and CD105 (Figure 2i), but not Oct4 (data not shown), indicating that they contain cells with stem or progenitor properties. ${ }^{15}$ We have also compared the gene expression profiles of Wnts in SFZ cells $v s$ chondrocytes, and found significant differences in expression of Wnt2b, Wnt4, Wnt5a, Wnt11 and Wnt16 (Figure 2j). Expression of other Wnt family genes was very low in both SFZ cell and chondrocyte cultures. The data indicate that SFZ cells have unique phenotypic characteristics that distinguish them from underlying chondrocytes. 



h

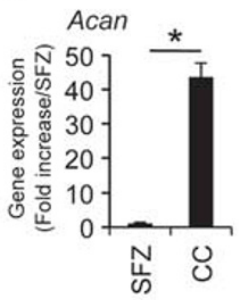

Chondrocyte-marker

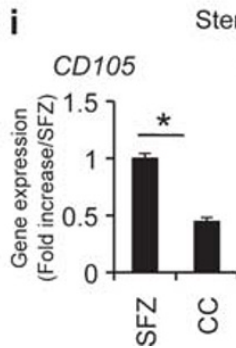

Stem cell marker
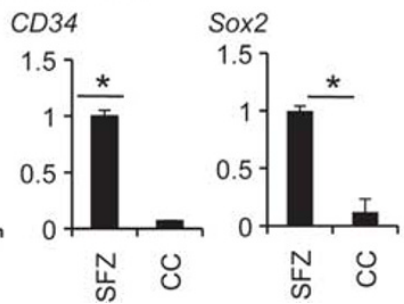

j
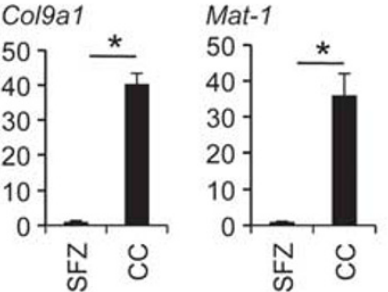

Figure 2 Isolation of superficial zone (SFZ) cells and gene expression analysis. (a) Sections of mouse neonatal epiphyseal ends stained with hematoxylin and eosin (H\&E) after incubation with $0.25 \%$ trypsin for $1 \mathrm{~h}$. (b and c), Sections of mouse neonatal epiphyseal ends from Gdf5Cre;RosaR26R-LacZ mice stained for $\beta$-galactosidase after incubation with $0.25 \%$ trypsin for $1 \mathrm{~h}(\mathbf{b})$, followed by 1.5 -h digestion with $173 \mathrm{U} / \mathrm{ml}$ collagenase (c). Dotted lines demarcate future secondary ossification center (SOC). (d) Section of tibial epiphyseal end immunostained for $\alpha 5$ integrin; nuclei were counter-stained with DAPI (blue). Bars represent $200 \mu \mathrm{m}$ for (a) and $20 \mu \mathrm{m}$ for (b-d). (e, f), Phase contrast images of SFZ (e) and chondrocyte (f) cultures. Pictures were taken $48 \mathrm{~h}$ after plating. $(\mathbf{g}-\mathbf{j})$, Total RNAs were prepared from SFZ or chondrocyte (CC) confluent cultures and subjected to quantitative PCR analysis for SFZ markers (g: Proteoglycan 4 (Prg4), Ets-related gene (Erg) and tenascin C), chondrocytes marker (h: aggrecan (Acan), collagen 9 a1 (Col9a1) and matrilin-1 (Mat-1) or stem cell markers (i: CD105, CD34 and Sox 2). Gene expression of Wnt family genes was examined by PCR array (RT2 Profiler PCR array for Wnt signaling pathway). ${ }^{*} P<0.05$.

\section{Gene Array Analysis}

Next, we carried out genome-wide gene expression analyses to further characterize the phenotype and potentials of SFZ cells, and compare them with those of articular chondrocytes. Populations of SFZ cells and chondrocytes were isolated from compound Gdf5Cre;RosaR26R-EYFP transgenic mice by differential enzymatic digestion as above. The populations were further sorted by flow cytometry to purify eYFP-positive SFZ cells and articular chondrocytes, and immediately processed for RNA isolation without culturing. Gene array analyses showed that SFZ cells and articular chondrocytes expressed both predictable and unexpected sets of genes, and 170 genes showed over 2.0-fold statistical differences in gene expression levels at a threshold value set at 0.05 (Figure 3, Supplementary Table S1). Thus, compared with chondrocytes, the SFZ cells exhibited low expression of cartilage matrix genes including aggrecan, collagen 2 al, collagen 9 a1, collagen 11 al and matrillin 1, but higher expression of tenascin $C$ and CD44. Interestingly, the cells strongly expressed also a number of genes that were previously linked to joint disorders and articular cartilage degeneration, and including asporin, ${ }^{36}$ tumor necrosis factor alpha-induced protein $6,^{37}$ frizzled-related protein $^{38}$ and ERBB receptor feedback inhibitor $1 .{ }^{39}$ Functional genome-wide predictive analyses revealed that the genes differentially expressed by SFZ cells are highly associated with molecular networks of 'connective tissue disorders, genetic disorders, cellular assembly and organization' and 'cell-to-cell signaling and interaction, tissue development and cancer' (Supplementary Figures S1 and S2).

\section{Wnt/ $\beta$-Catenin Signaling and SFZ Cell Function}

To gain further insights into $\mathrm{Wnt} / \beta$-catenin signaling roles in the regulation of SFZ cell behavior and phenotype, SFZ cells in primary culture as above were maintained in control conditions or treated with Wnt3a, a stimulator of Wnt/ $\beta$-catenin signaling, for several days. In control cultures, the cells had become polygonal and epithelioid (Figure 4a), whereas the Wnt3a-treated cells were elongated and had 


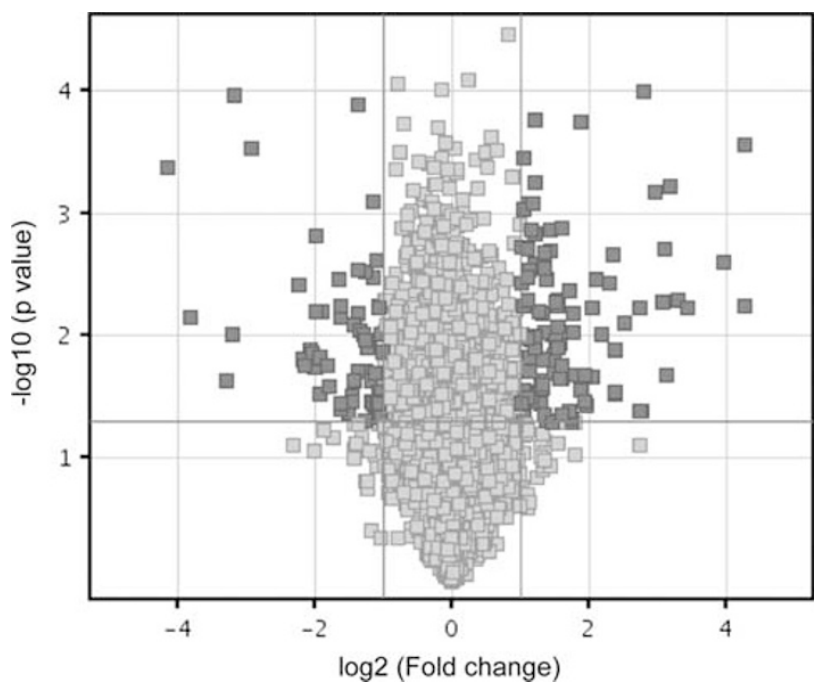

Figure 3 Volcano plot of microarray data. Plot depicts differences in superficial zone (SFZ) cell and articular chondrocyte expression patterns, and the dark gray plots represent more than or equal to 2.0-fold differentially expressed genes between the two groups at $P<0.05$.

grown in number considerably (Figure $4 \mathrm{~b}$ ). To characterize such proliferative response, SFZ cultures were continuously treated with Wnt3a and cell numbers were determined at each passage. Wnt3a treatment did increase SFZ cell number during the first and second passage over control values, but this effect dwindled by the third passage (Figure 4e). To confirm that the effects of Wnt3a on cell proliferation were due to $\beta$-catenin-dependent pathways, the cultures were co-treated with Dkk-1, an inhibitor of Wnt $/ \beta$-catenin signaling $^{40,41}$ (Figure 4g, Wnt3a vs Wnt3a + Dkk-1). Co-treatment with Dkk-1 inhibited the Wnt3a-induced morphological changes (Figure 4d) and proliferation (Figure 4e, P2 Wnt3a vs Wnt3a + Dkk-1).

To test whether $\beta$-catenin signaling is actually required for proliferation, we isolated SFZ cells from CagCreER; $\beta$-catenin $^{f l / f l}$ mice and treated them with $4 \mathrm{OTH}$ for 2 days to ablate $\beta$-catenin; companion cells were treated with vehicle only. Cells were then replated and monitored over time. Compared with vehicle-treated controls (Figure 5a), the $\beta$-catenindeficient cells did not proliferate well and became flat and spread over the culture dish superficial (Figure 5b). Immunoblot analysis confirmed that the tamoxifen-treated cultures contained barely detectable levels of $\beta$-catenin (Figure 5e, lane 2), whereas vehicle-treated cells contained obvious amounts (Figure 5e, lane 1). Cell number quantification at first and third passage showed that $\beta$-catenin ablation had strongly and continuously inhibited cell proliferation (Figure 5f), and the inhibition of cell proliferation was not rescued by treatment with Wnt3a (data not shown). To exclude that the inhibition of cell proliferation was due to non-specific side effects of $4 \mathrm{OTH}$, we prepared SFZ cultures from $\beta$-catenin ${ }^{\mathrm{f} / \mathrm{fl}}$ mice and treated them with $4 \mathrm{OHT}$. Treatment with $4 \mathrm{OHT}$ per se did not affect cell morphology
(Figure 5d) and proliferation (Figure 5f, $\beta$-cat ${ }^{\mathrm{fl} / \mathrm{fl}}$ ), as compared with vehicle-treated cultures (Figures $5 \mathrm{c}$ and $\mathrm{f}$ ).

Next, we tested whether Wnt/ $\beta$-catenin signaling affected gene expression of SFZ gene markers Prg4 and Erg over culture time and passage number. Cultures continuously treated with rWnt3a were able to maintain expression of those genes over several passages, whereas expression of those genes dwindled in control cultures over time (Figure 4f). Although Wnt3a treatment maintained expression of Prg4 and $\mathrm{Erg}$, it did not prevent the time-dependent loss of expression of the stem cell marker gene CD105 (Figure 4f). We co-treated SFZ cultures with Wnt3a and Dkk-1, or IWR1 , both of which inhibited Wnt3a-stimulated $\beta$-catenin signaling pathway (Figure $4 \mathrm{~g}$ ), and found that Dkk-1 and IWR-1 suppressed Wnt3a action on maintenance of Prg4 expression (Figure $4 \mathrm{~h}$ ). In addition, when we treated the cultures with $\mathrm{BIO}$ that is a GSK3 $\beta$ inhibitor and stimulates $\beta$-catenin signaling pathway (Figure $4 \mathrm{~g}$ ), we observed an increase in Prg4 expression similar to that following Wnt3a treatment (Figure 4h). It has been shown that Wnt3a also activates non-canonical Wnt pathway, including the JNK and $\mathrm{Ca}^{2+} /$ calmodulin pathways. ${ }^{41}$ However, inhibitors of these pathways did not affect and even enhanced Prg4 expression in Wnt3a-treated SFZ culture (Figure 4h). In addition, deficiency of $\beta$-catenin in P1 SFZ culture did not change the levels of Prg4, Erg, CD105 and type 10 collagen gene expression (Figure $5 \mathrm{~g}$ ), suggesting that $\beta$-catenin signaling may not directly regulate transactivation of these genes, though it is clearly required for cell proliferation and promotes maintenance of SFZ cell phenotype.

\section{SFZ Cell Differentiation Potentials}

In a final set of experiments, we analyzed whether the SFZ cells are able to undergo chondrogenesis in in vitro pellet cultures or after transplantation in vivo, and whether these potentials were modulated by $\mathrm{Wnt} / \beta$-catenin signaling. SFZ cells were expanded in control and Wnt3a-containing cultures through six passages and were then maintained for an additional week in pellet cultures in the absence of Wnt3a. Both pellet cultures expressed similar levels of chondrogenic matrix genes such as aggrecan, but Prg4 expression was much higher in Wnt3a-pretreated than control cultures (Figure 4h, Prg4).

To test SFZ cell differentiation potentials in vivo, SFZ cells isolated from Gdf5Cre;RosaR26R mice (to facilitate their monitoring in vivo) were cultured in presence or absence of Wnt3a for 7 days and transplanted subcutaneously in athymic mice. Both groups of SFZ cells formed ectopic solid tissue masses 1 week after transplantation (Figures 6a and c). Histological examination revealed that the control tissue composed of small and round cells (Figure 6b, arrows) and was positive for alcian blue staining (Figures $6 e$ and $f$ ) and type 2 collagen immunostaining (Figure 6i), whereas the Wnt3a-pretreated tissue contained more fibroblastic cells though it did stain with alcian blue (Figures $6 \mathrm{~g}$ and $\mathrm{h}$ ) and 

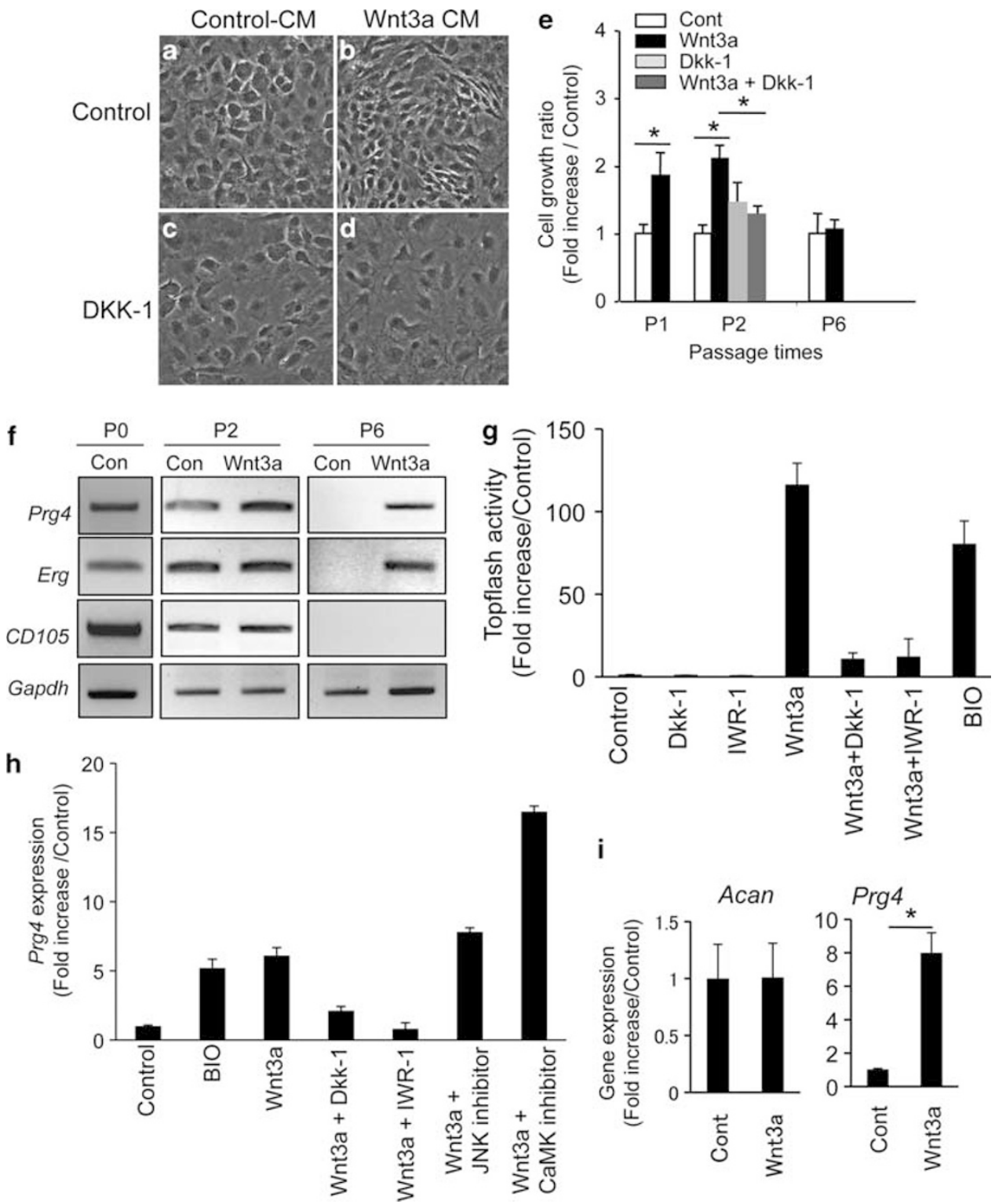

Figure 4 Effects of Wnt3a on proliferation and gene expression in superficial zone (SFZ) cultures. SFZ cells were isolated from epiphyseal cartilage of wild-type mice and serially passaged at the density of $4200 / \mathrm{cm}^{2}$ up to six times. (a-f and $\mathbf{i}$ ), The cultures were continuously treated with Wnt3a-containing conditioned medium (30\%) or control conditioned medium after the first passage in the presence or absence of $100 \mathrm{ng} / \mathrm{ml}$ of DKK-1. Phase contrast pictures were taken on day 4 in the second passage cultures (a-d). Cell numbers were counted at indicated passages; values are average and s.d. from three independent samples (e). Total RNAs were prepared from Wnt3a-treated or control SFZ cell cultures at indicated passages to analyze expression levels of Proteoglycan 4 (Prg4), Ets-related gene (Erg), CD105 and glyceraldehyde 3-phosphate dehydrogenase (Gapdh) by RT-PCR as described in Materials and Methods (f). Sixth passage cultures, treated with or without Wnt3a, were transferred into pellet cultures and cultured for 7 days. Total RNAs were then prepared to analyze expression level of aggrecan (Acan) or Prg4 (i). (g) The SFZ cells were transfected with Topflash Wnt reporter plasmid, treated with Wnt3a-containing conditioned medium (30\%) or control conditioned medium in the presence or absence of $6 \mathrm{BIO}(\mathrm{BIO}, 1 \mu \mathrm{g} / \mathrm{ml}), 100 \mathrm{ng} / \mathrm{ml}$ of DKK-1 or $10 \mu \mathrm{M}$ IWR-1 for $24 \mathrm{~h}$, and then the luciferase activity was measured. (h) The cultures were continuously treated with Wnt3a-containing conditioned medium (30\%) or control conditioned medium after 1st passage in the presence or absence of 6BIO (BIO, $1 \mu \mathrm{g} / \mathrm{ml}), 100 \mathrm{ng} / \mathrm{ml}$ of DKK-1, $10 \mu \mathrm{M} \mathrm{IWR-1}$, $10 \mu \mathrm{M} \mathrm{SP} 600125$ (JNK inhibitor) or $10 \mu \mathrm{M} \mathrm{KN}-93$ (Ca2 +/calmodulin-dependent protein kinase II inhibitor, CaMK inhibitor). Total RNAs were prepared from the SFZ cultures at passage 6 to analyze expression levels of Prg4 by real-time $\mathrm{PCR}$. ${ }^{\star} P<0.05$.

type 2 collagen antibodies (Figure 6k). Most of cells in both transplant tissues were positive to $\beta$-galactosidase staining (Figures $6 \mathrm{~m}-\mathrm{p}$ ), indicating that the ectopic tissues were largely composed of donor, but not host cells. We isolated total RNA from the ectopic tissues and examined gene expression of markers of SFZ cells and chondrocytes. Control tissues expressed Prg4 and aggrecan and the Wnt3a-pretreated tissues expressed slightly higher levels of these genes (Figures 6q and r). Interestingly, collagen 10 was expressed in control tissue, but its level was much lower in Wnt3a-pretreated 

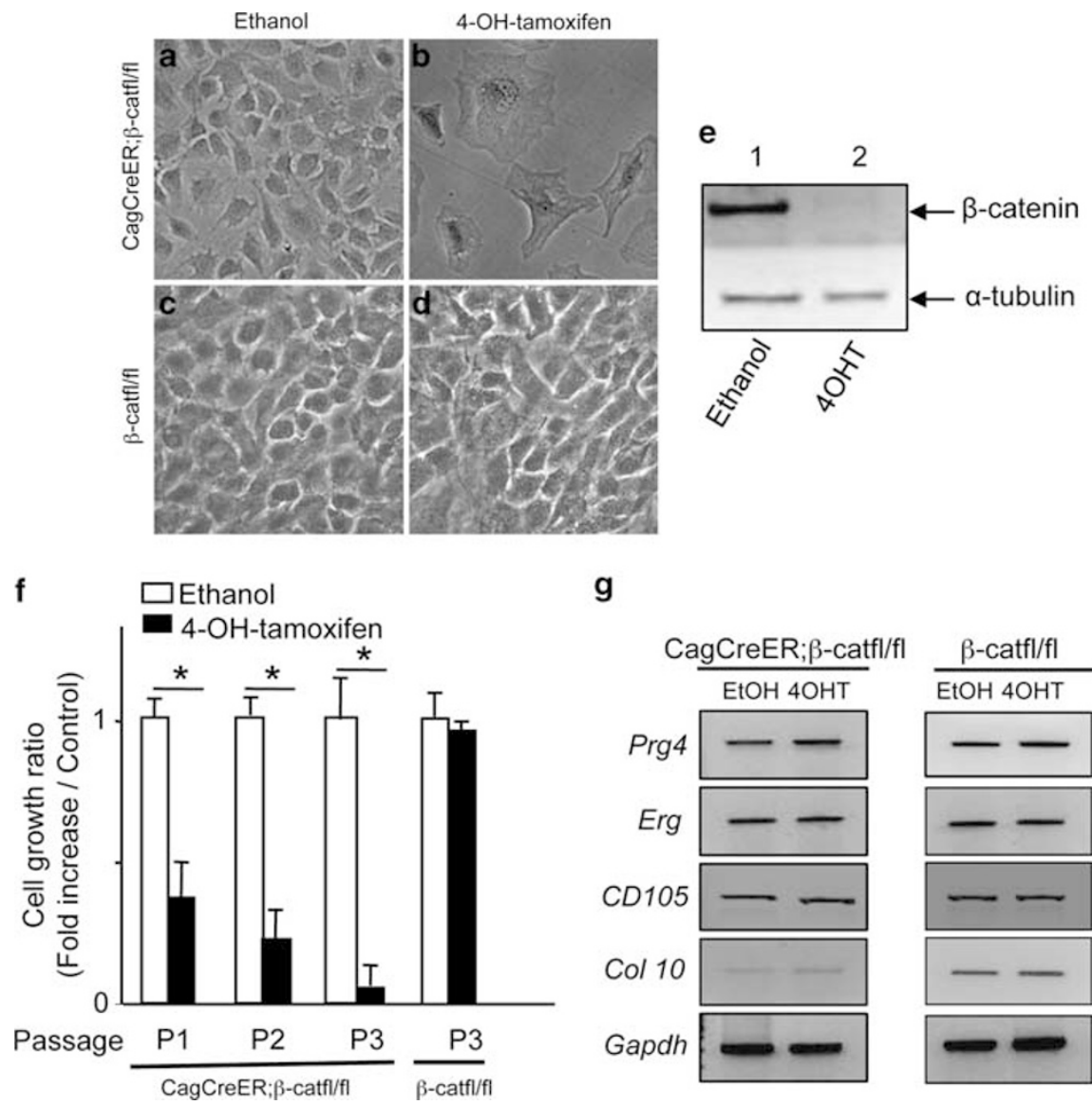

Figure 5 Effects of $\beta$-catenin ablation on proliferation and gene expression in superficial zone (SFZ) cultures. SFZ cells were isolated from epiphyseal cartilage of CagCreER; $\beta$-catenin ${ }^{f / / f l}$ or $\beta$-catenin ${ }^{f / f f l}$ mice. Cultures were serially passaged at the density of $4200 / \mathrm{cm}^{2}$ up to six times. The CagCreER/ $/$-catenin ${ }^{f / f f l}$ or $\beta$-catenin ${ }^{f / f l}$ cell cultures were treated with $1 \mu \mathrm{M}$ 4-hydroxytamoxifen (4OTH) or vehicle (ethanol) for 2 days just after the first passage, and no further treatment was performed. Cultures were passaged two more times. (a-d) Phase contrast pictures were taken on day 4 in the second passage cultures. (e) Cell lysates prepared from the first passage culture of CagCreER/ $\beta$-catenin ${ }^{f / f l}$ SFZ cells were subjected to immunoblot analysis for $\beta$-catenin or $\alpha$-tubulin. (f) Cell numbers were counted at indicated passages; values are average and s.d. from three independent samples. (h) Total RNAs were prepared from CagCreER/ $\beta$-catenin ${ }^{f / f l}$ or $\beta$-catenin ${ }^{\text {fl/fl }}$ cell cultures at P2 to analyze expression levels of Proteoglycan 4 (Prg4), Ets-related gene (Erg), CD105 and glyceraldehyde 3-phosphate dehydrogenase (Gapdh) by real-time-PCR. ${ }^{\star} P<0.05$.

tissue (Figure 6s), indicating that the transplanted control cells had progressed toward hypertrophy, whereas the Wnt3apretreated cells had retained an immature chondrocyte character.

In parallel experiments, we transplanted SFZ cells that lacked $\beta$-catenin. SFZ cells were isolated from CagCreER; $\beta$-catenin ${ }^{f l f l}$ mice, treated with $4 \mathrm{OTH}$ or vehicle as above, and then transplanted in athymic mice. Ectopic tissues formed by these $\beta$-catenin-deficient cells were histologically different from those formed by control cells (Figures 7a-d). They displayed round and larger cells (Figure $7 \mathrm{~b}$ ) that were intensely stained by alcian blue pericellularly, whereas control tissues were only moderately stained (Figures $7 \mathrm{c} v s \mathrm{~d}$ ). Interestingly the $\beta$-catenin-deficient tissues lacked a peripheral fibroblast layer (Figure 7b) that was evident in control tissues (Figure $7 \mathrm{a}$, arrows). Gene expression analysis showed that the $\beta$-catenin-deficient tissues were characterized by strong expression of aggrecan and collagen 10 (Figures $7 \mathrm{f}$ and $\mathrm{g}$ ) and low expression of Prg4 (Figure 7e), compared with control tissues. Thus, deletion of $\beta$-catenin induced a loss of SFZ cell character and stimulated chondrogenic differentiation.

\section{DISCUSSION}

We show here that $\mathrm{Wnt} / \beta$-catenin signaling has essential roles in the regulation of SFZ organization and function in vivo, and strongly supports proliferation and maintenance of SFZ cell phenotypic characteristics. The latter conclusion is based on direct analyses of SFZ cells made possible by our novel procedure by which the cells can be isolated from neonatal mouse articular cartilage and studied in vitro. Our gene array and in vitro studies also reveal that SFZ cells have expression and phenotypic profiles distinct from those of underlying articular chondrocytes, can maintain their in vivo articular 

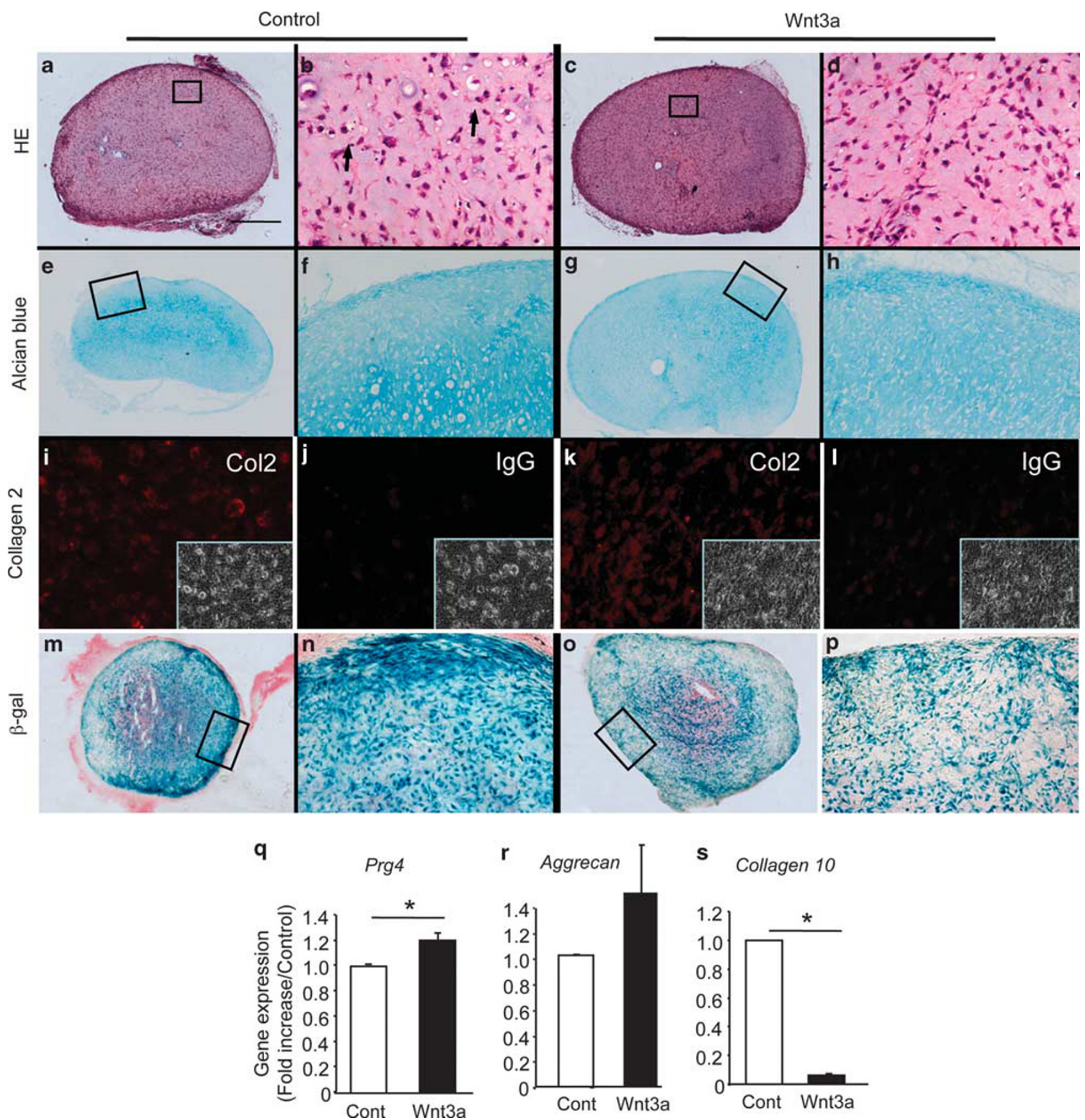

S Collagen 10

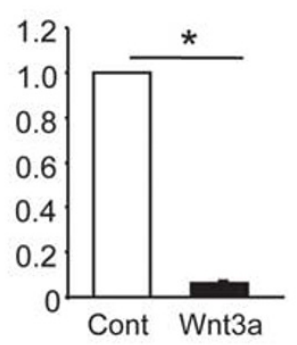

Figure 6 Histology and gene expression of transplanted superficial zone (SFZ) cells. Cells isolated from Gdf5Cre;RosaR26R-LacZ neonatal mice were subcultured at 1:10 ratio, treated with Wnt3a-containing conditioned medium ( $30 \% \mathrm{v} / \mathrm{v} ; \mathbf{c}, \mathbf{d}, \mathbf{g}, \mathbf{h}, \mathbf{k}, \mathbf{l}, \mathbf{o}, \mathbf{p})$ or control medium (a, b, e, f, i, j, $\mathbf{m}, \mathbf{n})$ until confluent, and then subcutaneously transplanted into athymic mice. Resulting ectopic tissue masses were harvested 1 week later and sections were stained with hematoxylin and eosin (a-d, HE) or alcian blue (e-h), or processed for collagen 2 immunostaining (i-l; i and $\mathbf{k}$ incubated with anti-collagen 2 antibody and $\mathbf{j}$ and $\mathbf{I}$ incubated with preimmune rabbit immunoglobulin (IgG)) or for $\beta$-galactosidase staining (m-p, $\beta$-gal). Samples were also used for expression analysis for Proteoglycan 4 (Prg4) (q), aggrecan (r) and collagen 10 (s, Col10). b, d, f, h, $\mathbf{n}$, and $\mathbf{p}$ are magnified images corresponding to squared areas in $\mathbf{a}, \mathbf{c}, \mathbf{e}, \mathbf{g}, \mathbf{m}$ and $\mathbf{o}$, respectively. The bar represents $200 \mu \mathrm{m}$ for $\mathbf{a}, \mathbf{C}, \mathbf{e}, \mathbf{g}, \mathbf{m}$ and $\mathbf{0}$, and $50 \mu \mathrm{m}$ for $\mathbf{b}, \mathbf{d}, \mathbf{f}, \mathbf{h}, \mathbf{j}-\mathbf{I}$, n and p. ${ }^{\star} P<0.05$.

SFZ characteristics in culture and have chondro-progenitor properties.

Superficial cells were previously isolated from bovine articular cartilage and found to exhibit chondro-progenitor properties, high colony formation efficiency and strong proliferative activity lasting over 45 cell population doubling. ${ }^{15}$ The SFZ cells we obtain from mouse epiphyseal ends actively proliferate until the third passage and essentially stop 

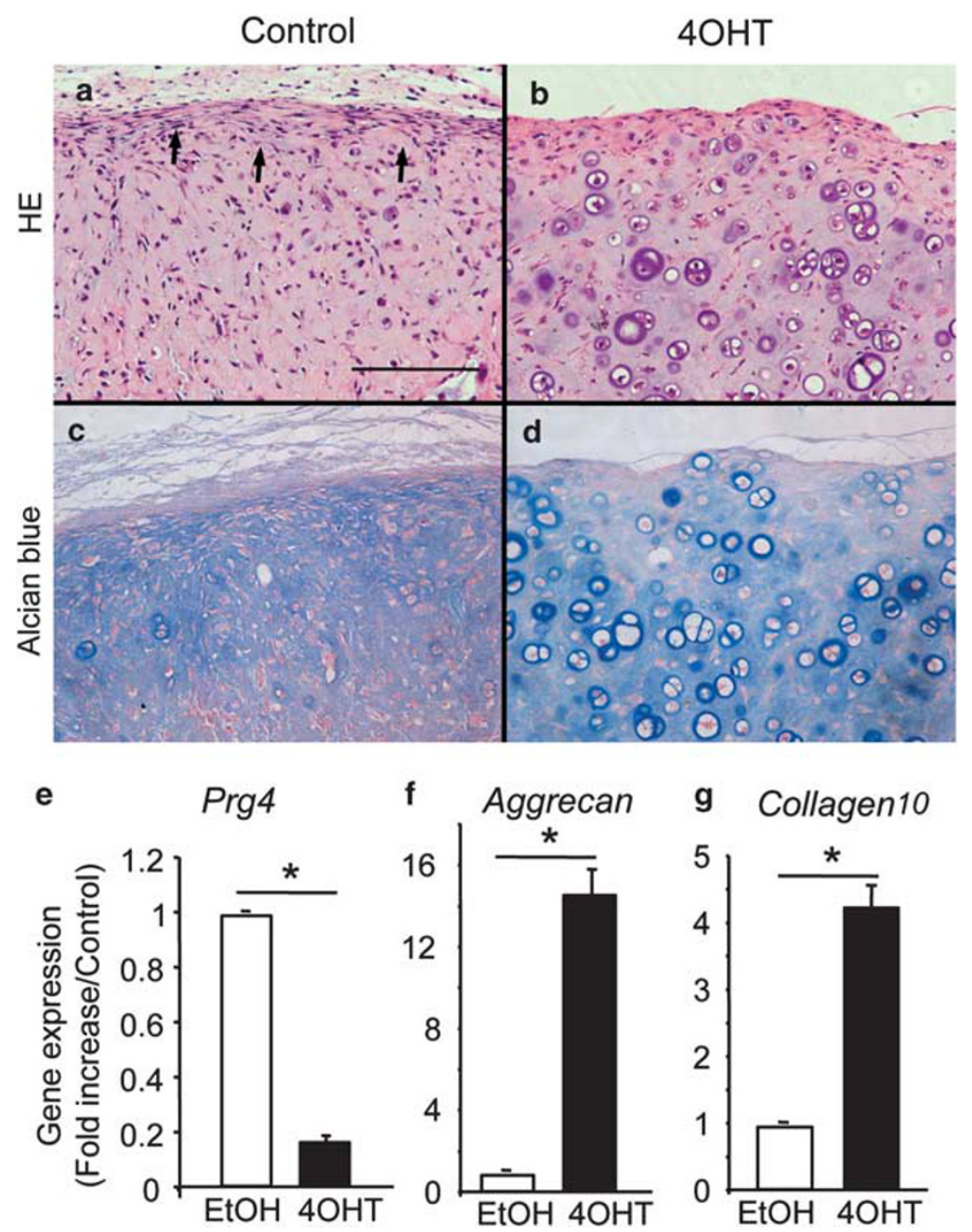

Figure 7 Histology and gene expression of transplanted $\beta$-catenin-deficient superficial zone (SFZ) cells. Cells isolated from CagCreER/ $\beta$-catenin ${ }^{f / f I}$ neonatal mice were subcultured at 1:10 ratio, treated with ethanol (a and $\mathbf{c}$ ) or $1 \mu \mathrm{M}$ 4-hydroxytamoxifen (b and $\mathbf{d}, 4 \mathrm{OHT}$ ) for 2 days, further cultured until confluent without 4-OHT and finally transplanted subcutaneously into athymic mice. Ectopic masses were harvested 1 week later, and subjected to hematoxylin and eosin (H\&E) staining (a and b) and alcian blue staining (c and d)) or gene expression analysis for Proteoglycan 4 (Prg4) (e), aggrecan (f) and collagen $10(\mathrm{Co} / 10)(\mathbf{g})$. Arrows indicate elongated cells surrounding the control transplant tissue. Bar represents $50 \mu \mathrm{m}$. ${ }^{\star} P<0.05$.

proliferating by the sixth passage. What could be the reasons behind these apparent conflicting results? One likely possibility is that our cultures contain the overall articular cell superficial population that may include genuine superficial cells expressing Prg4 and Erg, as well as progenitor or stem cells expressing genes such as CD105. We have not attempted yet to select for a progenitor subpopulation, as it was done in the bovine studies. Our interpretation is consistent with our findings that the mouse SFZ cultures express stem cell markers at thefirst passage, but not at the later passages. Once transplanted into athymic mice, the mouse SFZ cells form ectopic cartilaginous tissue as revealed by morphology, gene expression and production of a highly sulfated proteoglycans matrix. This indicates that SFZ cells do have chondrogenic potentials, could serve as a source of articular chondrocytes, and could have a key role in articular cartilage maintenance and appositional growth.
Several studies in a variety of systems have provided clear evidence for the importance of the SFZ in joint function, ${ }^{11,14,42,43}$ and more recent work points to the likely roles of SFZ cells in self-renewal and maintenance of articular cartilage. ${ }^{15,16}$ What has remained largely unclear is which signaling molecules and pathways regulate SFZ function, and our data indicate that the $\mathrm{Wnt} / \beta$-catenin signaling represents one such critical pathway. We now show that acute activation of Wnt/ $\beta$-catenin signaling in vivo increases cell number and thickness of the SFZ, and is accompanied by a proportional increase in Prg4 expression, whereas $\beta$-catenin ablation elicits the opposite effects. We also show that SFZ cells in vitro maintain their phenotypic characteristics under chronic stimulation of $\mathrm{Wnt} / \beta$-catenin signaling elicited by exogenous Wnt3a. A recent report has suggested that Wnt3a stimulates both canonical and non-canonical Wnt signaling in articular chondrocytes, and that the non-canonical 
pathway is important for inhibition of cartilage matrix gene expression, whereas the canonical $\beta$-catenin-dependent pathway promotes cell proliferation. ${ }^{41}$ Our data indicate that stimulation of cell proliferation and maintenance of SFZ phenotype by Wnt3a treatment are dependent on $\beta$-catenin signaling. Although untreated SFZ cell cultures displayed increases in collagen 2 and aggrecan expression over passage number, expression of these chondrocyte markers remained low in companion Wnt3a-treated cultures. Because co-treatment with Dkk-1 or IWR-1 did not alter these outcomes, it is very likely that Wnt3a inhibited cartilage gene matrix expression through a non-canonical pathway in SFZ cells as recently reported in articular chondrocyte cultures. ${ }^{41}$

In reciprocal experiments, we show that SFZ cells deficient in $\beta$-catenin lost proliferating activity and gave rise to ectopic cartilaginous tissue masses when transplanted. Thus, it is clear from our experiments that $\beta$-catenin function is important to maintain SFZ cell phenotypic characteristics and to prevent SFZ cells from expressing an articular chondrocyte phenotype. It remains unclear whether specific Wnt proteins control $\beta$-catenin signaling in SFZ, whether other signaling molecules are involved and whether $\beta$-catenin may also be required for cell adhesion functions in the regulation of SFZ organization and function.

Our findings indicate that acute activation of $\mathrm{Wnt} / \beta$-catenin signaling induces thickening of SFZ in vivo and SFZ cell proliferation in vitro. Thus, it is possible and plausible that a similar acute local stimulation of $\mathrm{Wnt} / \beta$-catenin signaling could have therapeutic value and joint disease prevention applications. It could be used to transiently reactivate SFZ proliferation, stimulate phenotypic expression and encourage the cells to repopulate articular cartilage and restore function. These enticing possibilities have to be weighted against evidence that activation of $\mathrm{Wnt} / \beta$-catenin signaling may cause articular cartilage degeneration and joint disease when chronic or ongoing for protracted time periods. ${ }^{19,27,44}$ Thus, a therapeutic strategy would be particularly useful in situations in which endogenous signaling is low and the joints are not in their terminal degenerative state. In such cases, signaling could be activated for a short period during which SFZ cell proliferation and phenotypic expression could be stimulated without causing long-term damage to articular tissue.

In summary, our study has revealed that the function and organization of articular cartilage SFZ are strongly influenced and regulated by $\mathrm{Wnt} / \beta$-catenin signaling. This pathway could be critical for long-term maintenance of articular cartilage and joint function, and has the potential to serve as a possible therapeutic target to stimulate SFZ function and in turn joint regeneration.

Supplementary Information accompanies the paper on the Laboratory Investigation website (http://www.laboratoryinvestigation.org)

\section{ACKNOWLEDGEMENTS}

This study was supported by NIH grants AR050507, AG025868 and AR046000, and Japanese Government Ministry of Education Grant-in-Aid for
Young Scientists (B) 22791977. We thank Ms A Hargget, C Saunders and D Pilchak for technical assistance and Ms Jasinski for critical reading. We also thank Drs F Watt (UK London Research Institute), N Tsumaki (Osaka University) and S Mackem ( $\mathrm{NCl}$ ) for providing the $\beta$-catER plasmid, collagen $11 a 1$ promoter/enhancer plasmid and Col2CreER transgenic mice.

\section{DISCLOSURE/CONFLICT OF INTEREST}

The authors declare no conflict of interest.

1. Goldring MB, Goldring SR. Osteoarthritis. J Cell Physiol 2007;213: 626-634.

2. Ikegawa S. New gene associations in osteoarthritis: what do they provide, and where are we going? Curr Opin Rheumatol 2007;19: 429-434.

3. Horton Jr WE, Bennion P, Yang L. Cellular, molecular, and matrix changes in cartilage during aging and osteoarthritis. J Musculoskelet Neuronal Interact 2006;6:379-381.

4. Hunziker EB, Michel $M$, Studer D. Ultrastructure of adult human articular cartilage matrix after cryotechnical processing. Microsc Res Tech 1997:37:271-284.

5. Khan IM, Gilbert SJ, Singhrao SK, et al. Cartilage integration: evaluation of the reasons for failure of integration during cartilage repair. A review. Eur Cell Mater 2008;16:26-39.

6. Pacifici M, Koyama E, Iwamoto M. Mechanisms of synovial joint and articular cartilage formation: recent advances, but many lingering mysteries. Birth Defects Res C Embryo Today 2005;75:237-248.

7. Archer CW, Dowthwaite GP, Francis-West P. Development of synovial joints. Birth Defects Res C Embryo Today 2003;69:144-155.

8. Murphy JM, Heinegard R, Mclntosh A, et al. Distribution of cartilage molecules in the developing mouse joint. Matrix Biol 1999;18:487-497.

9. Schumacher BL, Block JA, Schmid TM, et al. A novel proteoglycan synthesized and secreted by chondrocytes of the superficial zone of articular cartilage. Arch Biochem Biophys 1994;311:144-152.

10. Iwamoto M, Tamamura Y, Koyama E, et al. Transcription factor ERG and joint and articular cartilage formation during mouse limb and spine skeletogenesis. Dev Biol 2007;305:40-51.

11. Korhonen RK, Wong M, Arokoski J, et al. Importance of the superficial tissue layer for the indenation stifness of articular cartialage. Med Eng Phys 2002;24:99-108.

12. Arokoski JPA, Hyttinen MM, Helminen $\mathrm{HJ}$, et al. Biomechanical and structural characteristics of canine femoral and tibial cartilage. J Biomed Master Res 1999;48:99-107.

13. James DF, Fick GM, Baines WD. A mechanism to explain physiological lubrication. J Biomech Eng 2010; 132:071002.

14. Chan SM, Neu CP, Duraine G, et al. Atomic force microscope investigation of the boundary-lubricant layer in articular cartilage. Osteoarthritis Cartilage 2010;18:956-963.

15. Dowthwaite GP, Bishop JC, Redman SN, et al. The surface of articular cartilage contains a progenitor cell population. J Cell Sci 2004;117 (Pt 6):889-897.

16. Hattori S, Oxford C, Reddi AH. Identification of superficial zone articular chondrocytes stem/progenitor cells. Biochem Biophys Res Commun 2007:358:99-103.

17. Francis-West PH, Parish J, Lee $\mathrm{K}$, et al. BMP/GDF-signalling interactions during synovial joint development. Cell Tissue Res 1999;296:111-119.

18. Koyama E, Shibukawa $Y$, Nagayama $M$, et al. A distinct cohort of progenitor cells participates in synovial joint and articular cartilage formation during mouse limb skeletogenesis. Dev Biol 2008;316: 62-73.

19. Schett G, Zwerina J, David JP. The role of Wnt proteins in arthritis. Nat Clin Pract Rheumatol 2008;4:473-480.

20. Chun JS, Oh H, Yang S, et al. Wnt signaling in cartilage development and degeneration. BMB Rep 2008;41:485-494.

21. Day TF, Yang Y. Wnt and hedgehog signaling pathways in bone development. J Bone Joint Surg Am 2008;90Suppl 1:19-24.

22. Hartmann C. Skeletal development-Wnts are in control. Mol Cells 2007;24:177-184.

23. Yuasa T, Kondo N, Yasuhara R, et al. Transient activation of Wnt/\{beta\}catenin signaling induces abnormal growth plate closure and articular cartilage thickening in postnatal mice. Am J Pathol 2009;175: 1993-2003. 
24. Nakamura E, Nguyen MT, Mackem S. Kinetics of tamoxifen-regulated Cre activity in mice using a cartilage-specific CreER(T) to assay temporal activity windows along the proximodistal limb skeleton. Dev Dyn 2006;235:2603-2612.

25. Rountree RB, Schoor $M$, Chen $H$, et al. BMP receptor signaling is required for postnatal maintenance of articular cartilage. PLoS Biol 2004;2:e355.

26. Soriano P. Generalized lacZ expression with the ROSA26 Cre reporter strain. Nat Genet 1999;21:70-71.

27. Yuasa T, Otani T, Koike T, et al. Wnt/beta-catenin signaling stimulates matrix catabolic genes and activity in articular chondrocytes: its possible role in joint degeneration. Lab Invest 2008;88:264-274.

28. Saraiya $M$, Nasser $R$, Zeng $Y$, et al. Reversin enhances generation of progenitor-like cells by dedifferentiation of annulus fibrosus cells. Tissue Eng Part A 2010;16:1443-1455.

29. Thirunavukkarasu M, Addya S, Juhasz B, et al. Heterozygous disruption of Flk-1 receptor leads to myocardial ischaemia reperfusion injury in mice: application of affymetrix gene chip analysis. J Cell Mol Med 2008;12:1284-1302

30. Jay GD. Lubricin and surfacing of articular joints. Curr Opin Orthop 2004;15:355-359.

31. Rhee DK, Marcelino J, Baker M, et al. The secreted glycoprotein lubricin protects cartilage surfaces and inhibits synovial cell overgrowth. J Clin Invest 2005;115:622-631.

32. Jay GD, Torres JR, Rhee DK, et al. Association between friction and wear in diarthrodial joints lacking lubricin. Arthritis Rheum 2007;56: 3662-3669.

33. Jones $A R$, Flannery CR. Bioregulation of lubricin expression by growth factors and cytokines. Eur Cell Mater 2007;13:40-45.

34. Hayes AJ, MacPherson S, Morrison $\mathrm{H}$, et al. The development of articular cartilage: evidence for an appositional growth mechanism. Anat Embryol (Berl) 2001;203:469-479.
35. Dowthwaite GP, Flannery CR, Flannelly J, et al. A mechanism underlying the movement requirement for synovial joint cavitation. Matrix Biol 2003;22:311-322.

36. Kizawa $\mathrm{H}, \mathrm{Kou}$ I, lida $\mathrm{A}$, et al. An asparatic acid repeat polymorphism in asporin inhibits chondrogenesis and increases susceptibility to osteoarthritis. Nat Genet 2005;37:138-144.

37. Bayliss MT, Howat SL, Dudhia J, et al. Up-regulation and differentia expression of the hyaluronan-binding protein TSG- 6 in cartilage and synovium in rheumatoid arthritis and osteoarthritis. Osteoarthritis Cartilage 2001;9:42-48.

38. Loughlin J, Dowling B, Chapman K, et al. Functional variants within the secreted frizzled-related protein 3 gene are associated with hip osteoarthritis in females. Proc Natl Acad Sci USA 2004;101: 9757-9762.

39. Zhang YW, Su Y, Lanning N, et al. Targetd disruption of Mig- 6 in the mouse genome leads to erly onset degenerative joint disease. Proc Natl Acad Sci USA 2005;102:11740-11745.

40. Kawano Y, Kypta R. Secreted antagonists of the Wnt signalling pathway. J Cell Sci 2003;116(Pt 13):2627-2634.

41. Nalesso G, Sherwood J, Bertrand J, et al. WNT-3A modulates articular chondrocyte phenotype by activating both canonical and noncanonical pathways. J Cell Biol 2011;193:551-564.

42. Crockett R, Grubelnik A, Roos S, et al. Biochemical composition of the superficial layer of articular cartilage. J Biomed Master Res 2006;82: 958-964.

43. Silver FH, Bradica G, Tria A. Relationship among biomechanical, biochemical, and cellular changes associated with osteoarthritis. Crit Rev Biomed Eng 2001;29:373-391.

44. Zhu M, Tang $\mathrm{D}, \mathrm{Wu} \mathrm{Q}$, et al. Activation of beta-catenin signaling in articular chondrocytes leads to osteoarthritis-like phenotype in adult beta-catenin conditional activation mice. J Bone Miner Res 2009;24:12-21. 